Check for updates

Cite this: RSC Adv., 2019, 9, 9006

\title{
An integrated microchannel biosensor platform to analyse low density lactate metabolism in HepG2 cells in vitro
}

\begin{abstract}
Shengli Mi, (D) $\dagger^{\text {abe }}$ Jingjing Xia, (D) $\dagger^{\mathrm{ab}}$ Yuanyuan $\mathrm{Xu}^{\mathrm{ab}}$ Zhichang $\mathrm{Du} \mathrm{a}^{\mathrm{ab}}$ and Wei Sun ${ }^{\star a b c d}$
In this study, we developed an electrochemical microchannel biosensor platform to analyse lactate metabolism in cells. This biosensor platform was fabricated by photolithography, thin-film deposition and microfluidic technology. A kind of functional biomaterial was prepared by mixing lactate oxidase, single-walled carbon nanotubes and chitosan, and platinum as working and blank electrodes of the biosensor was modified by a thin Prussian blue layer. The lactate biosensor was obtained by dropping functional biomaterials on the electrode. The results demonstrated that the sensitivity of the electrochemical biosensor was up to $567 \mathrm{nA} \mathrm{mM} \mathrm{mm}^{-1} \mathrm{~mm}^{-2}$ and the limit of detection was $4.5 \mu \mathrm{M}$ (vs. Ag/ $\mathrm{AgCl}$ as the counter/reference electrode). The biosensor used to quantitatively detect metabolic lactate concentrations in HepG2 cells cultured with cancer drugs showed high sensitivity, selectivity and stability, and has potential applications in organ-on-a-chip and tissue engineering technologies, which typically involve low concentrations of metabolites.
\end{abstract}

Received 26th January 2019

Accepted 8th March 2019

DOI: 10.1039/c9ra00694j

rsc.li/rsc-advances carbon, ${ }^{20,21}$ and screen-printed carbon ink, ${ }^{22,23}$ among others. Inorganic Prussian blue, which is obtained by electrodeposition, shows better catalytic activity and higher selectivity for $\mathrm{H}_{2} \mathrm{O}_{2}$ detection in the presence of $\mathrm{O}_{2}$ compared with $\mathrm{Pt}$ in neutral medium. ${ }^{21} \mathrm{~A}$ thin Prussian blue layer of biosensors plays an important role in the measurement of low concentrations of analyte measurement cell assay due to its electrocatalytic character. $^{20}$ Functional biomaterials mainly include specific enzymes for target biomarkers and biopolymers for enzyme immobilization and stabilization, minimizing interference from other substances and reducing interfacial imped-

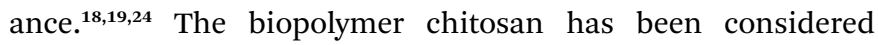
a suitable candidate for biosensors because of its biocompatibility, strong adhesion, good hydrophilicity and film-forming ability. ${ }^{25-27}$ Sometimes, carbon nanotubes, which have abundant functional groups, are typically incorporated into functional biomaterials as electron transfer mediators and electrocatalytic mediums to improve the sensitivity and stability of biosensors. ${ }^{27-30}$

The measurement of metabolites from cell cultures is an important tool in cancer cell research and drug screening, ${ }^{1}$ and lactate is an important parameter of metabolism ${ }^{31}$ and can be used to track cell's performance and metabolic activity. ${ }^{\mathbf{1 8 , 3 2}}$ Changes in metabolism play a pathological role in the development of cancer. ${ }^{33}$ Anticancer drugs that alter the metabolism can be added for understanding metabolic characterization of cancer cells. Furthermore, the concentrations of metabolites in low cell number or density, such as those found in organ-on-achip and microtissue applications, are less than those found in the human body. ${ }^{18,19}$ Therefore, it is extremely critical that 
biosensors have high sensitivity and low detection limits for accurately measuring low concentrations of target analytes in complex biological environments of cell cultures.

In this work, we reported an amperometric lactate biosensor based on electrodes modified by Prussian blue and the lactate oxidase enzyme immobilized by chitosan-carbon nanotubes. The small detection platform biosensors integrated with micro flow channels demonstrated good selectivity and a high sensitivity of $567 \mathrm{nA} \mathrm{mM}^{-1} \mathrm{~mm}^{-2}$. The small platform was demonstrated in a cell culture measurement, and the concentrations of lactate in human cancer cell cultures added anticancer drugs were quantified. Our platform, that detects bioanalytes at low concentrations and high-sensitivity, could likely be applied in drug screening, toxicology and personalized cancer diagnosis based on organ-on-a-chip technology.

\section{Experimental section}

\section{Materials and apparatus}

A glass substrate (B270, $100 \pm 2 \mathrm{~mm}$ diameter, $500 \mu \mathrm{m}$ thickness), 5-fluorouracil (5-FU, 99\% purity, $25 \mathrm{mg}$ ), and L-lactate ( $\geq 98 \%$ purity) were obtained from Shanghai Aladdin Biochemistry Technology Co., Ltd (Shanghai, China). The hepatic cell line HepG2 (ATTC) was obtained from Shanghai Zhong Qiao Xin Zhou Biotechnology Co., Ltd (Shanghai, China), and cultured according to the manufacturer's instructions. DMEM (highglucose containing $400 \mathrm{mM}$ L-glutamine, $4500 \mathrm{mg} \mathrm{L}^{-1}$ glucose and sodium pyruvate), penicillin-streptomycin solution (SV30010) and phosphate-buffered saline $(1 \times)$ (PBS) were obtained from HyClone (Beijing, China). Polydimethylsiloxane (PDMS, Dow Corning) was purchased from Suzhou Research Materials Microtech Co., Ltd (Suzhou, China). Lactate oxidase (LOx, $\geq 20$ units per mg solid, $100 \mathrm{U}$ ) from Aerococcus viridans was obtained from Shanghai Yanye Co., Ltd (Shanghai, China). Vincristine sulfate salt (VCS, 98\% purity, $25 \mathrm{mg}$ ) was purchased from Shanghai Macklin Biochemical Co., Ltd (Shanghai, China). Acetate (HPLC, $\geq 99.9 \%$ purity), potassium ferricyanide $\left(\mathrm{K}_{3} \mathrm{Fe}(\mathrm{CN})_{6}, \mathrm{AR}, \geq 99.5 \%\right.$ purity), iron chloride hexahydrate $\left(\mathrm{FeCl}_{3} \cdot 6 \mathrm{H}_{2} \mathrm{O}\right.$, ACS grade), chitosan (CS, deacetylation degree $\geq 95 \%$, viscosity 100-200 mPa.s) and single-walled carbon nanotubes (CNTs, $\geq 95 \%$ purity) were obtained from Shanghai Aladdin Biochemistry Technology Co., Ltd (Shanghai, China). Acetone was purchased from Xilong Scientific, and potassium chloride (KCl) was purchased from Shanghai Lingfeng Chemical Reagent Co., Ltd (Shanghai, China). Hydrochloric acid (HCl) was obtained from Huachengda Co., Ltd (Zhuhai, China). Platinum (Pt), silver (Ag), and titanium ( $\mathrm{Ti})(\geq 99.99 \%$ purity) were obtained from Zhongnuo Advanced Material Technology Co., Ltd (Beijing, China). Fetal bovine serum (FBS) was obtained from Shanghai Zhong Qiao Xin Zhou Biotechnology Co., Ltd (Shanghai, China).

A sputtering platform used for thin-film deposition was obtained from Microelectronics of the Chinese Academy of Sciences (Beijing, China). An ultrasonic homogenizer was made in Ningbo Scientz Biotechnology Co., Ltd (Ningbo, China). The vacuum was obtained from Shanghai Yiheng Scientific Instrument Co., Ltd (Shanghai, China). 6-well cell culture plates were obtained from Corning (Shenzhen) Management Co., Ltd
(Shenzhen, China). The CHI 700E electrochemical instrument was purchased from Shanghai Chenhua Instrument Co., Ltd (Shanghai, China). The incubator was purchased from Thermo Fisher Scientific (China) Co., Ltd (Shanghai, China). The peristaltic pump was purchased from Baoding Natong Pump Manufacturing Co., Ltd (Hebei, China).

\section{Electrode array fabrication}

The multi-electrode biosensor array was composed of four electrodes for cell culture metabolite analysis. The fabrication processes for the multi-electrode mainly used photolithography, thin-film deposition technology and lift-off. Fig. 1 shows the details. Briefly, a $500 \mu \mathrm{m}$ transparent glass substrate was thoroughly cleaned before the electrode array was patterned using shadow mask A by photolithography with a positive resist. Then, $30 \mathrm{~nm}$ of Ti and $50 \mathrm{~nm}$ of Pt were sequentially sputtered on the substrate by the sputtering platform, and the Ti/Pt electrode arrays appeared after the lift-off process in acetone (Fig. 1(b)). Another photolithography step was implemented to form the counter/ reference electrode pattern using shadow mask B. Then, a 100 nm-thick Ag film was deposited on the Ti/Pt surface utilizing ebeam sputtering technology (Fig. 1(c)). The substrate was rinsed in acetone to remove the positive resist. To keep the biosensors insulated from the external environment, the last photoresist was spin-coated and patterned onto a non-working area (Fig. 1(d)). The pads of the electrodes were exposed after the array was washed in acetone. Finally, the electrode array in Fig. 1(e) was formed.

\section{Enzyme immobilization}

Enzyme immobilization is critical for electrochemical biosensors, and the immobilization-method seriously affects the life of a biosensor. ${ }^{34}$ In this study, we prepared a biomaterial, that was mixed with CS (good biocompatibility for enzymes) and CNTs (extremely high electron mobility) to immobilize lactate oxidase. First, CS was dispersed in $2 \%$ acetic acid and magnetically stirred for $2 \mathrm{~h}$ at room temperature to prepare a 1\% CS solution. Then, CNTs were sufficiently dispersed for $30 \mathrm{~min}$ in CS solution (2 $\mathrm{mg}$ $\mathrm{mL}^{-1}$ ) by an ultrasonic homogenizer. The CS/CNTs precursor solution was stored at a $4{ }^{\circ} \mathrm{C}$ when not in use. To prepare the functional biomaterial, a $10 \mathrm{mg} \mathrm{mL}^{-1}$ lactate oxidase solution was prepared by dissolving lactate oxidase in PBS ( $\mathrm{pH} 7.0)$. The lactate oxidase solution and the precursor solution were thoroughly mixed at a $1: 2$ ratio by volume. The CS/CNTs/LOx solution was ready for the electrochemical biosensor.

\section{Microchannel fabrication}

A micro flow channel (Fig. 2) was fabricated by transfer of PDMS into a mould, which was previously prepared by photolithography. Generally, a silicon (Si) wafer was heated and spin-coated with SU8 photoresist (Fig. 2(b)) after cleaning in alcohol. The prebake was exposed to ultraviolet light through the shadow mask followed by heating. Finally, the pattern of the microchannel (Fig. 2(c)) was obtained by alternate flushing with the SU8 developer and alcohol. The microchannel mould was obtained after drying with nitrogen. A 10:1 ratio of PDMS was thoroughly mixed and poured over the mould (placed in a Petri 
(a)

\section{Glass cleaning}

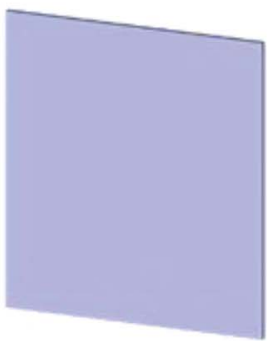

(f)

\section{Counter/Reference electrode}

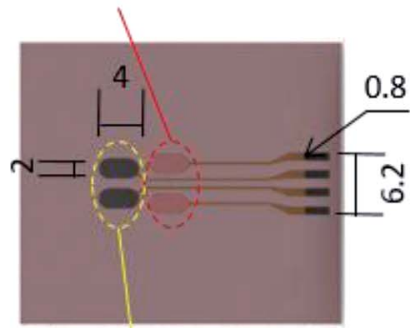

Working/blank electrode (b)

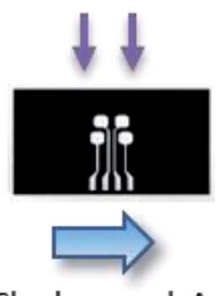

Shadow mask A

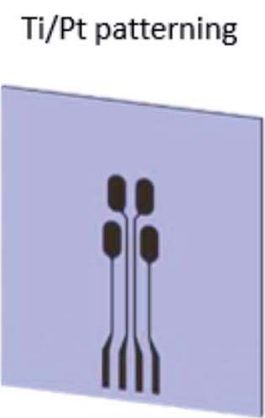

(e)

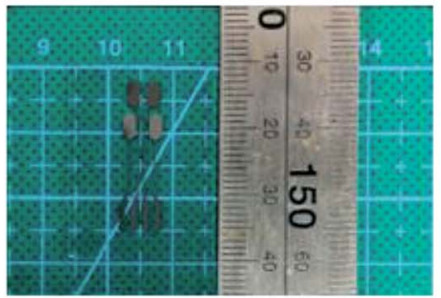

(c)

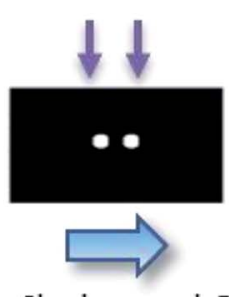

Shadow mask B
Ag patterning
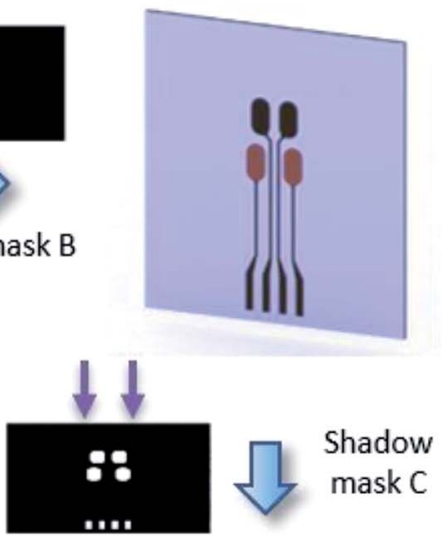

(d)
Photoresist insulation

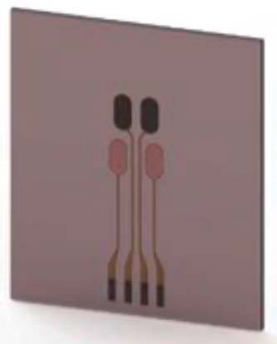

Fig. 1 Fabrication processes of the electrode array. (a) Glass substrate cleaned in acetone. (b) Patterning of the Ti/Pt electrodes by using shadow mask A through photolithography and e-beam sputtering, and eliminating the photoresist by using lift-off in acetone. (c) Photolithography and patterning of the Ag electrodes using shadow mask B by e-beam sputtering followed by lift-off in acetone. (d) The photoresist insulating layer patterned by shadow mask C. (e) Image of the electrode array. (f) Close-up schematic of the biosensor electrode array (mm).

dish) followed by placing in a vacuum for 20 min and baking at $85{ }^{\circ} \mathrm{C}$ for $1 \mathrm{~h}$. Then, the PDMS was taken from the mould and formed into the designed shape after the PDMS solidified. The smallest size of the microchannel $(200 \mu \mathrm{m}$ in height) was 300 $\mu \mathrm{m}$ in diameter, and the largest was $11 \mathrm{~mm}$ in diameter.

\section{Integration of the biosensor platform}

Integration of the enzyme biosensor was achieved by modifying the functional biomaterial film on a Prussian blue/platinum $(\mathrm{PB} / \mathrm{Pt})$ electrode. For the lactate biosensor, lactate is converted by lactate oxidase, and the intermediate $\mathrm{H}_{2} \mathrm{O}_{2}$ is oxidized at the surface of the $\mathrm{PB} / \mathrm{Pt}$ working electrode. The reaction process of lactate under lactate oxidase conditions is as follows:

$$
\begin{gathered}
\text { lactate }+\mathrm{O}_{2} \rightarrow \text { pyruvate }+\mathrm{H}_{2} \mathrm{O}_{2} \\
\mathrm{H}_{2} \mathrm{O}_{2} \rightarrow \mathrm{O}_{2}+2 \mathrm{H}^{+}+2 \mathrm{e}^{-}
\end{gathered}
$$

In the electrode array (Fig. 1(f)), Pt acted as the working electrode and blank electrode due to high chemical stability and perfect electrocatalytic activity for $\mathrm{H}_{2} \mathrm{O}_{2}{ }^{35}$ The $\mathrm{Ag} / \mathrm{AgCl}$ electrodes were fabricated as counter/reference electrode by dropcasting $10 \mu \mathrm{L}$ of $0.1 \mathrm{M} \mathrm{FeCl}_{3}$ solution on top of the $\mathrm{Ag}$ electrodes for $1 \mathrm{~min}$. Then, the electrode array was scanned for one cycle at a rate of $25 \mathrm{mV} \mathrm{s}^{-1}$ by cyclic voltammetry (CV) from $-5 \mathrm{~V}$ to $0 \mathrm{~V}$ (vs. $\mathrm{Ag} / \mathrm{AgCl}$ ) in a fresh Prussian blue solution configured with $2.5 \mathrm{mM} \mathrm{K}_{3} \mathrm{Fe}(\mathrm{CN})_{6}, 2.5 \mathrm{mM} \mathrm{FeCl}_{3}, 100 \mathrm{mM} \mathrm{KCl}$ and $100 \mathrm{mM} \mathrm{HCl}$. A thinner layer of Prussian blue, which can enhance the sensitivity of the lactate biosensor, was deposited onto the working/blank electrode. The lactate biosensor was obtained by injecting $5 \mu \mathrm{L}$ of CS/CNTs/LOx solution on top of the $\mathrm{PB} / \mathrm{Pt}$ working electrode, whereas the same volume of $\mathrm{CS} /$ CNTs solution was used on the blank electrode. The biosensors were stored at $4{ }^{\circ} \mathrm{C}$ when not in use.

The pads of the electrodes were connected with a printed circuit board (PCB, Fig. 3(a)) using an ultraviolet light-curing adhesive (purchased from a market). The PCB was personally designed using an Altium Designer and was produced by a commercial manufacturer (Shenzhen, China). PDMS and glass showed good adhesion and facilitated the integration of the biosensors and the microchannel is showed in Fig. 3(a).

\section{Cell culture}

HepG2 hepatic cells were cultured in DMEM supplemented with $10 \%$ fetal bovine serum and $1 \%$ penicillin/streptomycin at 
(a)

(a)

\section{Silicon cleaning}

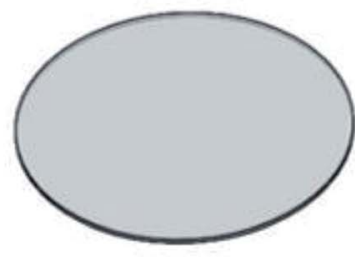

(f)

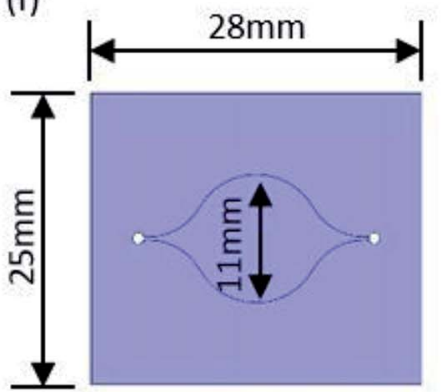

(b)
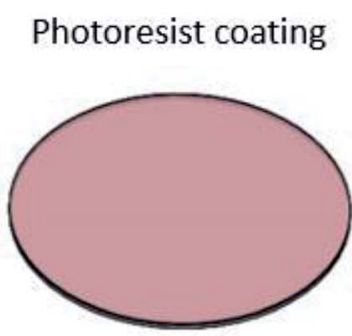

(e)

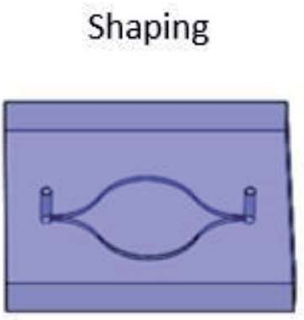

(c)
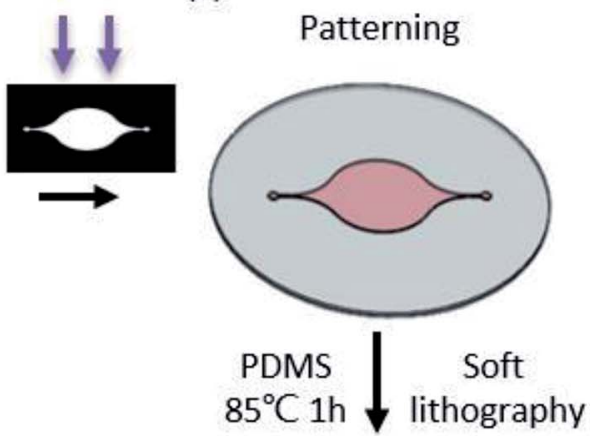

(d)

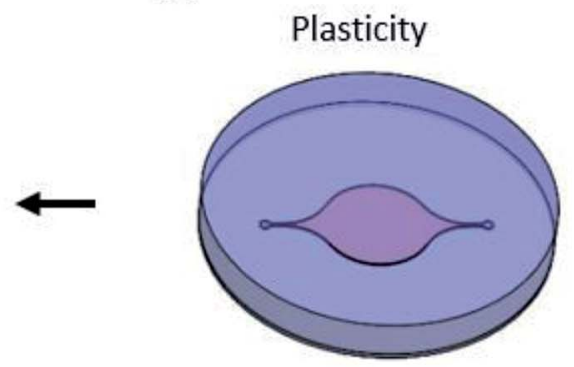

Fig. 2 Structuration diagrams of microchannel. (a) Silicon wafer cleaning. (b) Spinning coating with SU8 photoresist. (c) Mould patterning. (d) Soft lithography with PDMS. (e) Shaping with the desired size. (f) Dimension label of microchannels (mm).
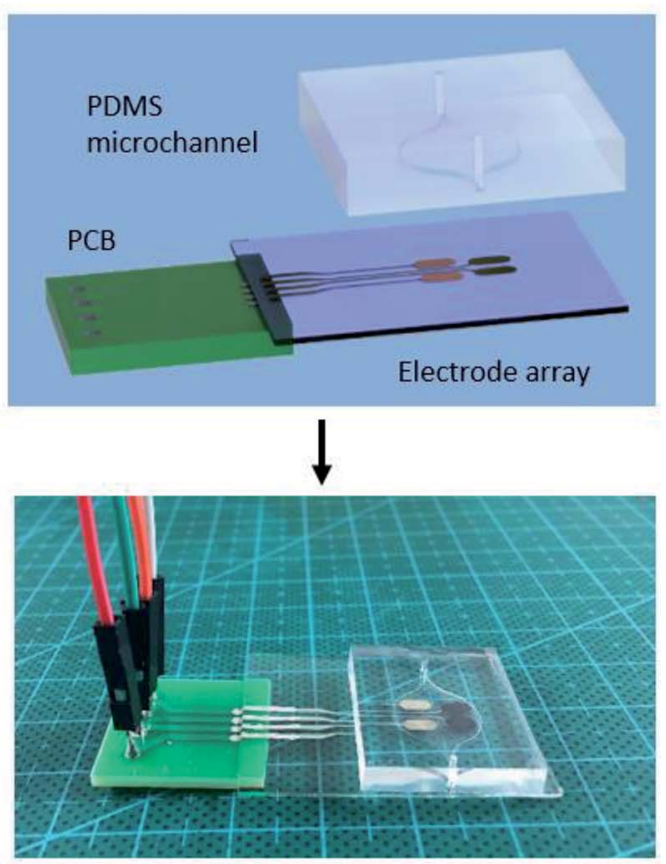

(b)

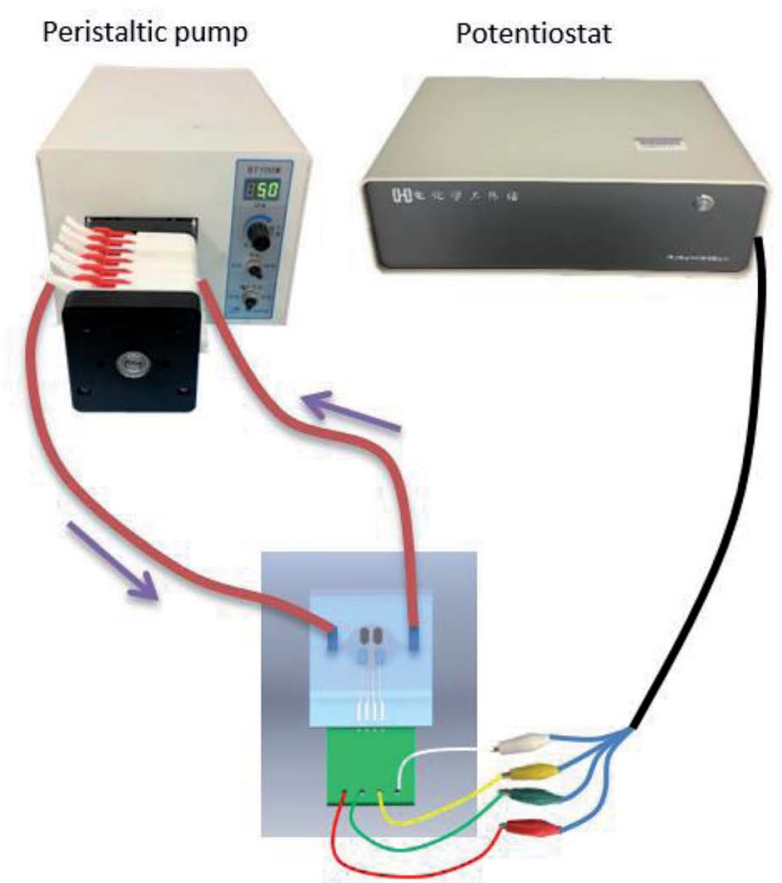

Fig. 3 (a) Demonstration of the microchannel biosensor platform integrated PDMS microchannel with PCB-electrode array. (b) Schematic of the PDMS microchannel-biosensor detection platform.

$37{ }^{\circ} \mathrm{C}$ in an incubator with a $5 \% \mathrm{CO}_{2}$ atmosphere. When the HepG2 cells were cultivated to the eighth generation, the cells were trypsinized and transferred from a Petri dish to a 6-well cell culture plate. The cells were seeded at a density of $2.5 \times 10^{5}$ cells per well in $2 \mathrm{~mL}$ of culture medium and were cultured as described above. Following $24 \mathrm{~h}$ of incubation and adhesion, $0.5 \mathrm{~mL}$ of drug solution (100 or $150 \mu \mathrm{M} 5$-FU and 10 or $15 \mu \mathrm{g}$ $\mathrm{mL}^{-1}$ VCS, respectively) was added to assay well. Conversely, 
$0.5 \mathrm{~mL}$ of medium was added to the control wells. 5-FU is sensitive to light and should be kept in the dark. After the cells were starved for $48 \mathrm{~h}$ in the absence of drug and different 5-FU and VCS concentrations, the media was collected for testing.

\section{Electrochemical detection protocols}

All experimental measurements were performed with a potential of $200 \mathrm{mV} v s$. $\mathrm{Ag} / \mathrm{AgCl}$ with a $\mathrm{CHI} 700 \mathrm{E}$ electrochemical instrument in different solutions at room temperature. Fig. 3(b) shows a schematic of the platform along with the PDMS micro flow channel for the biosensing studies. The microchannel device was attached to the potentiostat instrument through the PCB, and the inlet of the micro flow channel was connected to a peristaltic pump. For amperometric enzymatic biosensors, the liquid should remain laminar or stationary to ensure a steady signal during a measurement; therefore, diffusion is the only factor that affects oxidation at the electrode. In this study, we used a flow speed of $5 \mu \mathrm{L} \min ^{-1}$ to simulate the dynamic physiological environment. ${ }^{36}$ A total of $25 \mu \mathrm{L}$ of different concentrations of lactate solutions were injected into the channel for analysis. The platform was washed three times using PBS ( $\mathrm{pH}$ 7.0), and the blank electrode was used to eliminate the influence of an uncertain background.

\section{Result and discussion}

\section{Biosensor calibration}

The calibration values of the biosensor were obtained by detecting different lactate concentrations at a fixed potential of $200 \mathrm{mV}$. Lactate solutions ranging from $0 \mathrm{mM}$ to $1 \mathrm{mM}$ were prepared by adding lactate to PBS at $\mathrm{pH} 7.0$ and were injected into the microchannel at a typical flow rate of $5 \mu \mathrm{L} \mathrm{min}{ }^{-1}$. The correspondence between the current and the lactate concentrations can be characterized by the amperometric $i-t$ curve of the potentiostat instrument. Fig. 4 shows that the lactate biosensor showed a positive linear correlation between current signals and lactate concentrations as well as a highly selective characteristic.

Fig. 4(a) shows the data of amperometric curves measured in real-time and $5 \mathrm{~min}$ for each sample. The sensitivity of the biosensor calculated from the linear fitting of the calibration curve (Fig. 4(b)) was up to $567 \mathrm{nA} \mathrm{mM}^{-1} \mathrm{~mm}^{-2}$, which was (a)

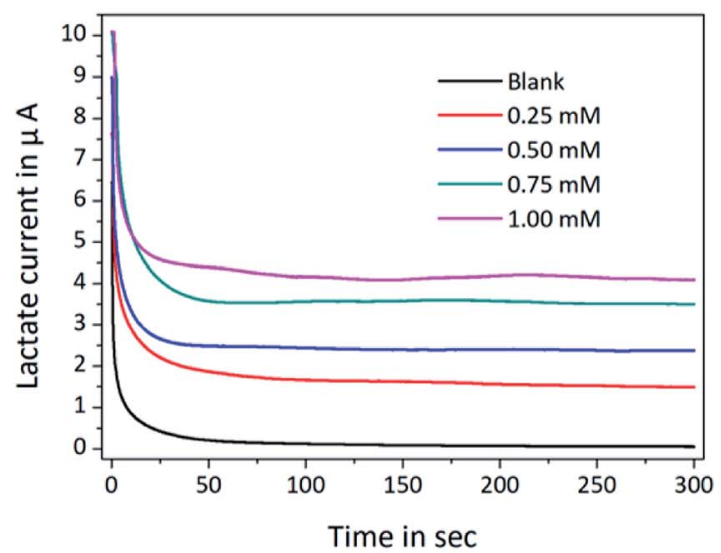

(c)

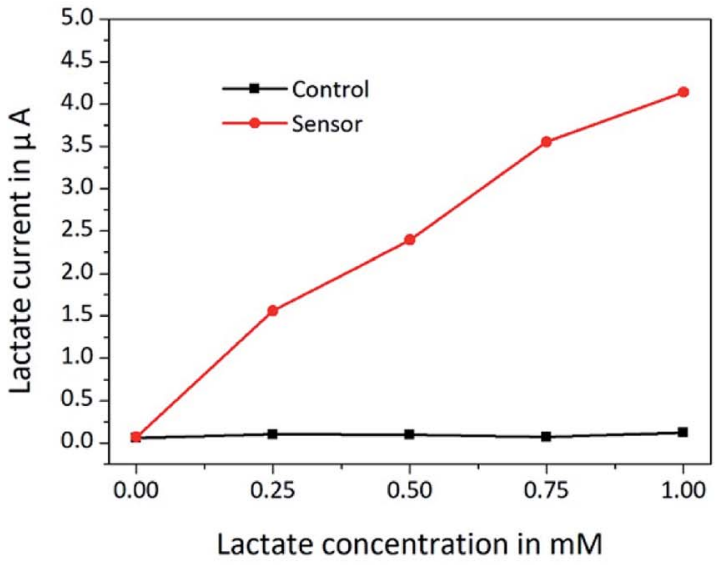

(b)

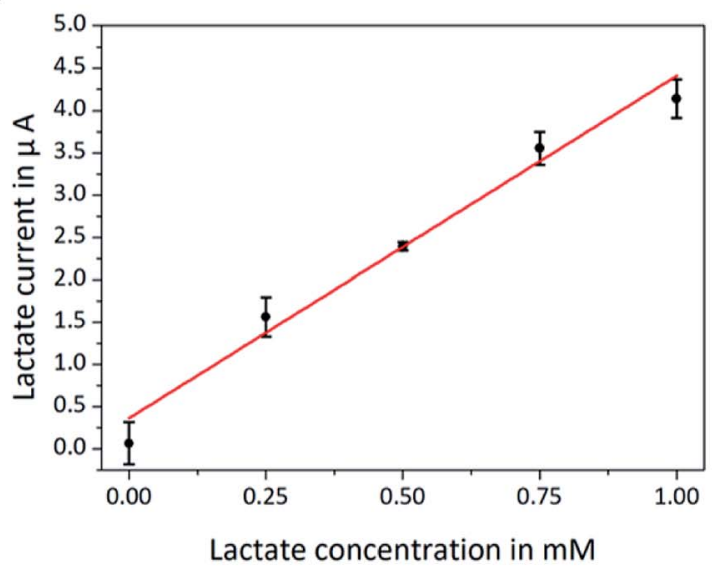

(d)

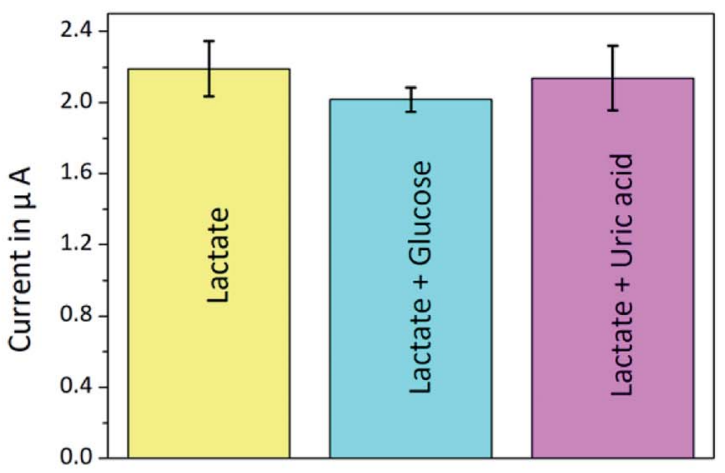

Fig. 4 (a) Amperometric $i-t$ curves of the biosensor platform based on the detection of different lactate concentrations. (b) Lactate calibration curve of the biosensor. (c) The data from the working electrode and the blank electrode were measured, which demonstrated the linearity and (d) the selectivity of the biosensor. The concentrations of the samples were $0.43 \mathrm{mM}$ lactate, $0.43 \mathrm{mM}$ lactate and $0.25 \mathrm{mM}$ glucose, and $0.43 \mathrm{mM}$ lactate and $0.1 \mathrm{mM}$ uric acid, respectively. 
Table 1 Comparison of our biosensor with other lactate biosensors

\begin{tabular}{|c|c|c|c|c|c|c|}
\hline Matrix & Technique & Sensitivity & Limit of detection & Prussian blue & Microchannel & Ref. \\
\hline pHEMA & Electrochemical & $134 \mathrm{nA} \mathrm{mm}^{-2} \mathrm{mM}^{-1}$ & $5-30 \mu \mathrm{M}$ & No & No & 18 \\
\hline Chitosan & Electrochemical & $31 \mathrm{nA} \mathrm{mm}{ }^{-2} \mathrm{mM}^{-1}$ & - & Yes & No & 19 \\
\hline No & Electrochemiluminescence & & $3.132 \mu \mathrm{M}$ & No & Paper-based & 37 \\
\hline No & Electrochemiluminescence & & $35 \mu \mathrm{M}$ & No & Cloth-based & 38 \\
\hline No & Electrochemical & $0.3169 \mu \mathrm{A} \mathrm{mM}-1$ & $0.3 \mathrm{mM}$ & No & Cotton fabric-based & 39 \\
\hline
\end{tabular}

sufficiently high to explore small concentration variations in the low lactate concentration range. The detection limit ( $3 \sigma$ of the raw signal), which depends on the sensitivity of the biosensor, was obtained from the expression and was $4.5 \mu \mathrm{M}$. Importantly, the measured results and the combined microchannel and electrode array platform are expected to be further applied to the development of microfluidic biosensors. Although microfluidic biosensors are currently rapidly developing, they are still in the primary stage, and there is much work to be done before they are widely used outside of laboratories.

\section{Biosensor characterization}

Sensitivity, selectivity and stability are three important factors for biosensors. We computed the ultra-high sensitivity and low detection limit based on the fitting line (Fig. 4(b)). To remove non-specific impurity signals, the blank signal was subtracted (Fig. 4(c)). Fig. 4(b) and (c) shows that the lactate biosensor had linear characteristics. The selectivity of the biosensor platform was estimated by injecting the prepared impurity samples, such as $0.25 \mathrm{mM}$ glucose and $0.1 \mathrm{mM}$ uric acid, along with $0.43 \mathrm{mM}$ lactate. Standard concentrations of glucose and uric acid were mixed with lactate solution separately and detected by the biosensor platform. As shown in Fig. 4(d), glucose was observed to be the maximum interference for the lactate biosensor, and the coefficient of variation was approximately $4.6 \%$ under the same testing conditions. To demonstrate the stability of the lactate biosensor, $0.43 \mathrm{mM}$ lactate solution, as shown in Fig. 4(d), was analysed seven samples by the biosensor, and the variational coefficient of the repeated trials was $6.0 \pm 3.0 \%$ from the measured data. Table 1 shows the comparison of our biosensor with other lactate biosensors. $\mathrm{Gao}^{19}$ reported the use of Au modified with a thicker Prussian blue layer for lactate measurements to satisfy a wider range, while our work used Pt modified with a thinner Prussian blue layer for higher sensitivity. Electrochemiluminescence biosensors ${ }^{37-39}$ were reported for lactate detection in a disposable format, but the way of immobilized enzyme made them failed to continuously detect lactate. A comparison of a study conducted by Weltin ${ }^{18}$ with our study shows that Prussian blue can increase the sensitivity of the biosensor. This indicates that our biosensor indeed has a higher sensitivity and is fully capable of measuring low lactate concentrations in a cellular environment.

\section{Biosensor measurements}

To demonstrate the ability of the biosensor array to detect variations in the cell cultures, we used the biosensor to measure lactate in HepG2 cells cultured with medium containing different drug concentrations for the first time. $5-\mathrm{FU}^{40}$ and $\mathrm{VCS}^{41,42}$ have been widely used as anticancer drugs to treat tumours for many years, and both either prevent or inhibit the process cancer cell division leading to tumour cell apoptosis. Therefore, the amount of lactate decreases due to the reduction (a)

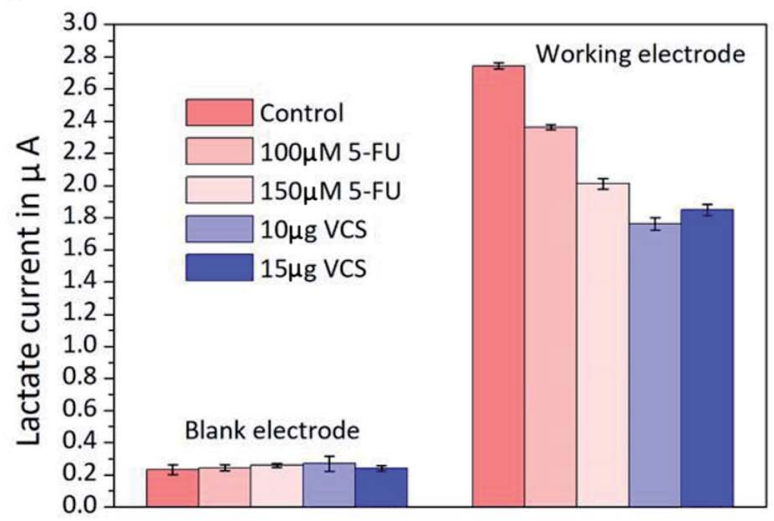

(b)

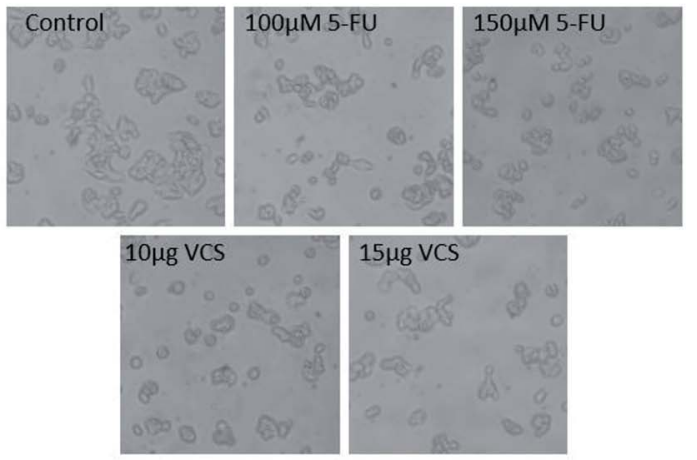

Fig. 5 (a) Parallel lactate detection in HepG2 cells in untreated medium compared to cells exposed to $100 \mu \mathrm{M} \mathrm{5-FU,} \mathrm{150} \mu \mathrm{M} 5$-FU, $10 \mu \mathrm{g} \mathrm{mL}{ }^{-1}$ VCS and $15 \mu \mathrm{g} \mathrm{mL}{ }^{-1}$ VCS after cultivation for $48 \mathrm{~h}$. (b) Morphology of HepG2 cells untreated medium compared to cells in media treated with 100 $\mu \mathrm{M}$ 5-FU, $150 \mu \mathrm{M}$ 5-FU, $10 \mu \mathrm{g} \mathrm{mL}{ }^{-1}$ VCS and $15 \mu \mathrm{g} \mathrm{mL}^{-1}$ VCS. 
in metabolic activity. By using the two drugs in a parallel test, we can better prove the reliability of our biosensors.

HepG2 cells were exposed to medium with 5-FU $(100 \mu \mathrm{M}$ or $150 \mu \mathrm{M})$ and VCS $\left(10 \mu \mathrm{g} \mathrm{mL}^{-1}\right.$ or $\left.15 \mu \mathrm{g} \mathrm{mL} \mathrm{m}^{-1}\right)$, and the same volume of medium without drugs was used to culture the cells. Lactate production by HepG2 cell metabolism for almost two days was detected by the platform. The untreated control HepG2 cells had an average lactate concentration of $588 \pm 58 \mu \mathrm{M}(n=3)$. Typically, the drug-treated cells had lower lactate concentrations. Fig. 5 shows that the HepG2 cells treated with $100 \mu \mathrm{M} 5$-FU had a concentration of $494 \pm 61 \mu \mathrm{M}(n=3)$, whereas the cells treated with $150 \mu \mathrm{M}$ 5-FU had a slightly lower concentration of $407 \pm 64$ $\mu \mathrm{M}(n=3)$. Fig. $5(\mathrm{a})$ shows that lactate production in response to $15 \mu \mathrm{g} \mathrm{mL} \mathrm{m}^{-1}$ of VCS $(367 \pm 59 \mu \mathrm{M})$ was greater than that in response to $10 \mu \mathrm{g} \mathrm{mL} \mathrm{m}^{-1}$ of VCS $(345 \pm 67 \mu \mathrm{M})$. The experimental results shown in Fig. 5(a) indicate that $10 \mu \mathrm{g} \mathrm{mL} \mathrm{m}^{-1}$ of VCS was more effective on liver cancer cells than $15 \mu \mathrm{g} \mathrm{mL}{ }^{-1}$ VCS.

Visual observation of the HepG2 cells under a microscope showed morphological changes in the parallel experiments (Fig. 5(b)). There was a distinct change in cellular morphology after exposure to 5-FU and VCS for $24 \mathrm{~h}$ compared with the control cells. Obviously, cultured cells with $10 \mu \mathrm{g} \mathrm{mL}^{-1} \mathrm{VCS}$ in the medium became abnormal in shape and grew independently. The morphology of HepG2 cells was in agreement with the results of the lactate measurement shown in Fig. 5(b) according to the relationship between lactate and cell activity as described above. Our biosensor has the ability to accurately detect lactate metabolism in cells and has potential applications in drug screening or toxicology.

\section{Conclusions}

In summary, a lactate-sensitive electrochemical biosensor with lactate oxidase, carbon nanotubes, chitosan, Prussian blue, and a Pt electrode was fabricated and calibrated in lactate-PBS solution. Fortunately, the enzyme biosensor showed good sensitivity of $567 \mathrm{nA} \mathrm{mM}^{-1} \mathrm{~mm}^{-2}$, low detection limits of 4.5 $\mu \mathrm{M}$ and excellent selectivity for sensing lactate. The platform easily integrated a micro flow system with the biosensor to control the volume at a low level. Our study indicates that biosensors are promising for drug screening by quantifying metabolic low density lactate changes in cultured cells, organon-a-chip or microtissue applications.

\section{Conflicts of interest}

There are no conflicts to declare.

\section{Acknowledgements}

This study was kindly supported by the Projects of Basic Research of Shenzhen, China (No. JCYJ 20170817162121275).

\section{References}

1 A. Weltin, K. Slotwinski, J. Kieninger, I. Moser, G. Jobst, M. Wego, R. Ehret and G. A. Urban, Lab Chip, 2014, 14, 138-146.
2 R. S. P. Malon, S. Sadir, M. Balakrishnan and E. P. Córcoles, BioMed Res. Int., 2014, 2014, 962903.

3 N. A. Mungroo and S. Neethirajan, Biosensors, 2014, 4, 472493.

4 E. B. Bahadir and M. K. Sezgintürk, Anal. Biochem., 2015, 478, 107-120.

5 H. C. Hong and H. J. Huang, Anal. Chim. Acta, 2003, 499, 4146.

6 Y. Michotte, M. Moors, D. Deleu, P. Herregodts and G. Ebinger, J. Pharm. Biomed. Anal., 1987, 5, 659-664.

7 D. Wu, Y. Wang, Y. Sun, N. Ouyang and J. Qian, Biomed. Chromatogr., 2015, 29, 1197-1202.

8 M. R. Moghadam, S. Dadfarnia, A. M. H. Shabani and P. Shahbazikhah, Anal. Biochem., 2011, 410, 289-295.

9 B. Habibi, M. Jahanbakhshi and M. H. Pournaghi-Azar, Electrochim. Acta, 2011, 56, 2888-2894.

10 L. Cui, J. Wu and H. Ju, Biosens. Bioelectron., 2015, 63, 276286.

11 W. Li, R. Ouyang, W. Zhang, S. Zhou, Y. Yang, Y. Ji, Y. Yang, K. Feng, X. Liang, M. Xiao and Y. Miao, Electrochim. Acta, 2016, 188, 197-209.

12 C. N. Kotanen, C. Tlili and A. Guiseppi-Elie, Appl. Biochem. Biotechnol., 2012, 166, 878-888.

13 C. N. Kotanen, O. Karunwi, F. Alam, C. F. T. Uyehara and A. Guiseppi-Elie, Electrochim. Acta, 2018, 267, 71-79.

14 J. Wang, J. Pharm. Biomed. Anal., 1999, 19, 47-53.

15 S. Chen and M. H. Shamsi, J. Micromech. Microeng., 2017, 27, 083001.

16 C. Lete, S. Lupu, B. Lakard, J. Y. Hihn and F. J. Del Campo, J. Electroanal. Chem., 2015, 744, 53-61.

17 V. D. Neff, J. Electrochem. Soc., 1978, 125, 886.

18 A. Weltin, S. Hammer, F. Noor, Y. Kaminski, J. Kieninger and G. A. Urban, Biosens. Bioelectron., 2017, 87, 941-948.

19 W. Gao, S. Emaminejad, H. Y. Y. Nyein, S. Challa, K. Chen, A. Peck, H. M. Fahad, H. Ota, H. Shiraki, D. Kiriya, D. H. Lien, G. A. Brooks, R. W. Davis and A. Javey, Nature, 2016, 529, 509-514.

20 A. A. Karyakin, O. V. Gitelmacher and E. E. Karyakina, Anal. Lett., 1994, 27, 2861-2869.

21 A. A. Karyakin, E. E. Karyakina and L. Gorton, Anal. Chem., 2000, 72, 1720-1723.

22 Y. Yao and C. Zhang, Biomed. Microdevices, 2016, 18, 92.

23 W. Guan, M. Liu and C. Zhang, Biosens. Bioelectron., 2016, 75, 247-253.

24 C. Kotanen, O. Karunwi and A. Guiseppi-Elie, Bioengineering, 2014, 1, 85-110.

25 K. Zhou, Y. Zhu, X. Yang, J. Luo, C. Li and S. Luan, Electrochim. Acta, 2010, 55, 3055-3060.

26 P. Sorlier, A. Denuzière, C. Viton and A. Domard, Biomacromolecules, 2001, 2, 765-772.

27 M. Satyanarayana, K. Y. Goud, K. K. Reddy and K. V. Gobi, Electrochim. Acta, 2015, 178, 608-616.

28 A. Abellán-Llobregat, L. Vidal, R. Rodríguez-Amaro, A. Canals and E. Morallón, Electrochim. Acta, 2018, 285, 284-291.

29 M. Satyanarayana, K. K. Reddy and K. V. Gobi, Anal. Methods, 2014, 6, 3772-3778. 
30 M. A. Ali, N. Singh, S. Srivastava, V. V. Agrawal, R. John, M. Onoda and B. D. Malhotra, Appl. Biochem. Biotechnol., 2014, 174, 926-935.

31 B. Enderle, A. Weltin, A.-K. Gellner, B. Fritsch, J. Kieninger and G. A. Urban, Biosens. Bioelectron., 2014, 61, 192-199.

32 G. Kroemer and J. Pouyssegur, Cancer Cell, 2008, 13, 472482.

33 I. Barberis, M. Martini, F. Iavarone and A. Orsi, Journal of Preventive Medicine and Hygiene, 2016, 57, E41-E46.

34 M. Zhang, S. Karra and W. Gorski, Anal. Chem., 2013, 85, 6026-6032.

35 S. Gao, P. J. Zhang, J. H. Guo, H. Chen, H. F. Xu, P. Liu, R. J. Yang and X. Zhu, World J. Gastroenterol., 2015, 21, 10443-10452.

36 G. Kaur, M. Tomar and V. Gupta, Sens. Actuators, B, 2018, 261, 460-466.
37 D. Wang, C. Liu, Y. Liang, Y. Su, Q. Shang and C. Zhang, J. Electrochem. Soc., 2018, 165, B361-B369.

38 Y. Yao, H. Li, D. Wang, C. Liu and C. Zhang, Analyst, 2017, 142, 3715-3724.

39 R. S. P. Malon, K. Y. Chua, D. H. B. Wicaksono and E. P. Córcoles, Analyst, 2014, 139, 3009-3016.

40 T. Liu, X. Wu, Y. Li, W. Lu, F. Zheng, C. Zhang, Q. Long, H. Qiu, Y. Li, Q. Ge, M. Chen, X. Yu, W. Chen, H. Zhang, W. Huang, M. Luo, W. Deng and L. Li, Cell. Physiol. Biochem., 2018, 46, 1365-1380.

41 Y. Öğünç, M. Demirel, A. Yakar and Z. İncesu, J. Microencapsulation, 2017, 34, 38-46.

42 S. Pyecroft, K. M. Li, A. Frimberger, C. Harmsen, B. de Mello Mattos, D. N. Phalen, A. Moore, S. Lola, S. Peck and A. J. McLachlan, PLoS One, 2013, 8, e65133.

43 A. Weltin, B. Enderle, J. Kieninger and G. A. Urban, IEEE Sens. J., 2014, 14, 3345-3351. 